\title{
INTERESTING LESIONS OF BONE MARROW WITH SPECIAL REFERENCE TO METASTASIS.
}

Dr. I. Sreelakshmi, Dr. P. Sunethri, Dr. B. Bheeshma, Dr. V. Geetha, Dr. P. Jijiya bai, Dr. O. Shravan Kumar, Dr. M. Anjani Devi, Dr. K. Ramakrishna Reddy.

1. Assistant Professor, Department of Pathology. Gandhi Medical College, Hyderabad.

2. Assistant Professor, Department of Pathology. Gandhi Medical College, Hyderabad.

3. Associate Professor, Department of Pathology. Gandhi Medical College, Hyderabad.

4. Assistant Professor, Department of Pathology. Gandhi Medical College, Hyderabad.

5. Professor \& Head of Department, Department of Pathology. Gandhi Medical College, Hyderabad.

6. Professor, Department of Pathology. Gandhi Medical College, Hyderabad.

7. Post Graduate, Department of Pathology. Gandhi Medical College, Hyderabad.

8. Post Graduate, Department of Pathology. Gandhi Medical College, Hyderabad.

\section{CORRESPONDING AUTHOR:}

Dr. I. Sreelakshmi, Gandhi Medical College, Musheerabad, Secunderabad, AP, Email id- $\underline{\text { Sreelakshmi123123@rediffmail.com, }}$ Ph- 009109346371707.

\begin{abstract}
:
BACKGROUND: Bone marrow examination is a commonly used diagnostic modality in the evaluation of hemato-oncological disorders and in patients with malignancies of visceral organs to detect metastasis. This study reviews clinical, hematological and pathological data of interesting cases with bone marrow involvement. Out of 490 bone marrow aspirations performed during a period of 4 years, 5 cases show metastatic carcinomatous deposits which included adenocarcinomas(3), squamous cell carcinoma(1) and neuroendocrine tumour(1), Non-Hodgkins lymphomas(2), storage disorder(2), granulomatous lesions(1), gelatinous transformation(1). Fever, generalized weakness, loss of appetite and loss of weight were the main symptoms. Anemia and pancytopenia were the main hematological findings. Dry tap was a significant finding in bone marrow aspiration in cases of metastatic cancers.
\end{abstract}

KEYWORDS : Bone Marrow Biopsy, Dry tap, Metastasis Cancer.

INTRODUCTION: Bone marrow examination is used commonly in evaluation of myeloid or lymphoid haematological malignancies, suspected storage disorders, plasma cell neoplasms, to detect infections \& reactive changes, metastasis in patients with cancer of visceral organs \& staging of tumors. Most common tumors that metastasize to bone in adults are prostrate, breast \& lung cancer and in children neuroblastoma, rhabdomyosarcoma, Ewing's sarcoma \& Retinoblastoma.

Infiltration of marrow is suspected in unexplained haematological abnormalities, fever of unknown origin, failure to thrive in infants, bone pains \& pathologic fractures, hot spots in PET CT and hypercalcemia, increased alkaline phosphatase.

We studied clinical, hematological, pathological data of interesting cases with bone marrow involvement.

MATERIALS AND METHODS: A total of 490 bone marrow aspirations performed between 2008- 2011 were analyzed. A total of 19 bone marrow aspirations, followed by biopsy were 
performed in patients with suspected bone marrow infiltration. Posterior iliac crest is common site preferred. Patients clinic history, haematological, \& pathological findings were reviewed retrospectively. Clinical profile included information about patient's age, sex, clinical history, physical findings, and provisional diagnosis. Peripheral blood picture, bone marrow study were reviewed. Leishman stain was done routinely. In addition special stains \& IHC were done where ever necessary.

RESULTS: Out of 19 cases with suspected bone marrow infiltration, 6 cases were Lymphoma/Leukemia, 5 cases showed metastatic bone marrow involvement, 4 cases were multiple myeloma, 2 cases of storage disorders, 1 case showed granulomatous lesion and 1 case showed gelatinous transformation. Of the 5 cases which showed metastatic deposits, 2 cases were from Carcinoma Breast, 1 case from Carcinoma Prostate, 1 case from Carcinoma Cervix and 1 case from Neuroblastoma. Imprints were positive in 2 cases of adenocarcinoma. Dry tap was seen in 3 cases. Primary site of the tumour was known in 4 cases. In one patient primary site was detected subsequent to detection of the bone marrow metastasis-Carcinoma prostate

\section{LESIONS FOUND IN THE BONE MARROW}

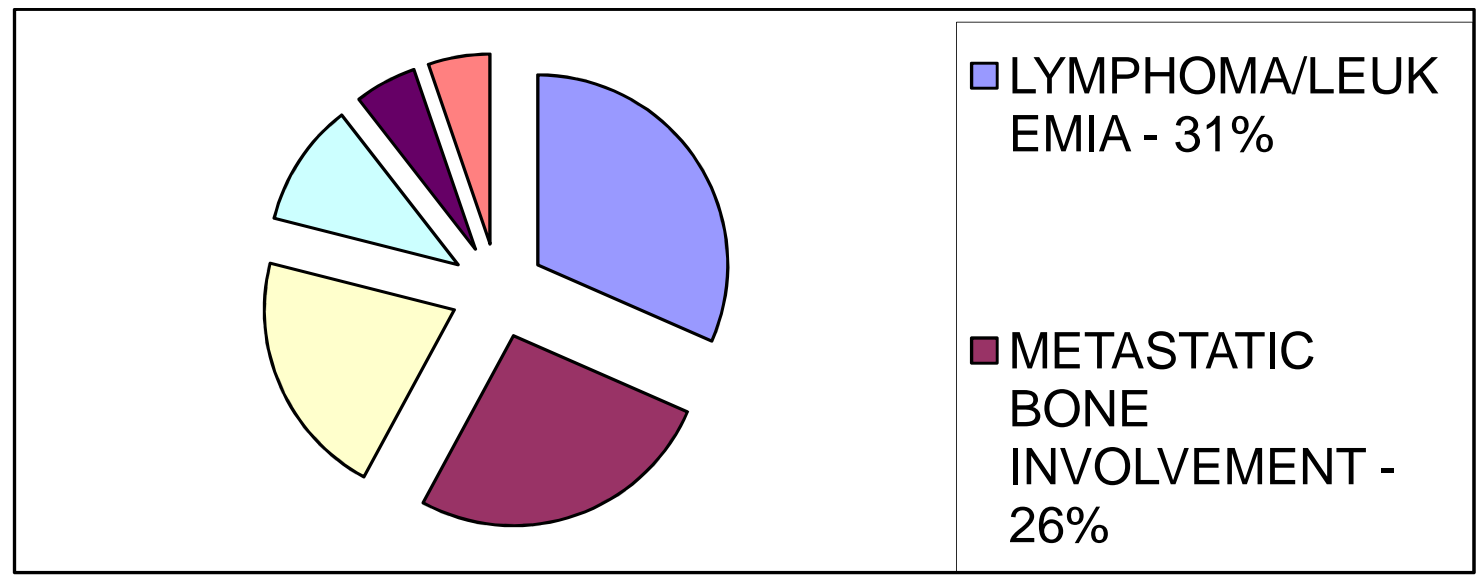

AGE AND SEX DISTRIBUTION:

\begin{tabular}{|l|c|c|}
\hline Lymphoma/Leukemia & 3 yrs & $\mathrm{F}$ \\
\hline Lymphoma/Leukemia & 5 yrs & $\mathrm{M}$ \\
\hline Lymphoma/Leukemia & $5 \mathrm{yrs}$ & $\mathrm{F}$ \\
\hline Lymphoma/Leukemia & $7 \mathrm{yrs}$ & $\mathrm{M}$ \\
\hline Lymphoma/Leukemia & $17 \mathrm{yrs}$ & $\mathrm{M}$ \\
\hline Lymphoma/Leukemia & $20 \mathrm{yrs}$ & $\mathrm{M}$ \\
\hline Metastatic involvement & & \\
\hline Ca Breast & $55 \mathrm{yrs}$ & $\mathrm{F}$ \\
\hline Ca Breast & $70 \mathrm{yrs}$ & $\mathrm{F}$ \\
\hline Ca Prostate & $70 \mathrm{yrs}$ & $\mathrm{M}$ \\
\hline Ca lung & $58 \mathrm{yrs}$ & $\mathrm{M}$ \\
\hline Neuroblastoma & $5 \mathrm{yrs}$ & $\mathrm{M}$ \\
\hline
\end{tabular}

Journal of Evolution of Medical and Dental Sciences/Volume1/ Issue3/July-Sept 2012. Page 161 
ORIGINAL ARTICLE

\begin{tabular}{|l|c|c|}
\hline Multiple Myeloma & $62 \mathrm{yrs}$ & $\mathrm{M}$ \\
\hline Multiple Myeloma & $64 \mathrm{yrs}$ & $\mathrm{M}$ \\
\hline Multiple Myeloma & $68 \mathrm{yrs}$ & $\mathrm{M}$ \\
\hline Multiple Myeloma & $57 \mathrm{yrs}$ & $\mathrm{M}$ \\
\hline Storage disorders & $3 \mathrm{yrs}$ & $\mathrm{M}$ \\
\hline Storage disorders & $9 \mathrm{~m}$ & $\mathrm{~F}$ \\
\hline Granulamtous lesions & $35 \mathrm{yrs}$ & $\mathrm{M}$ \\
\hline Gelatinous transformation & $40 \mathrm{yrs}$ & $\mathrm{M}$ \\
\hline
\end{tabular}

CLINICAL DETAILS

\begin{tabular}{|l|c||c|}
\hline $\begin{array}{l}\text { SYMPTOMS } \\
\text { Generalized weakness }\end{array}$ & $\begin{array}{c}\text { NO. OF CASES } \\
19\end{array}$ & $\begin{array}{c}\text { \% OF CASES } \\
100 \%\end{array}$ \\
\hline Loss of weight \& loss of appetite & 16 & $84 \%$ \\
\hline Bone pain & 10 & $52 \%$ \\
\hline Fever & 9 & $47 \%$ \\
\hline Low back pain & 8 & $42 \%$ \\
\hline Organomegaly & 7 & $36 \%$ \\
\hline Lymphadenopathy & 6 & $31 \%$ \\
\hline
\end{tabular}

HEMATOLOGICAL PROFILE

\begin{tabular}{|l|c||c|}
\hline $\begin{array}{l}\text { PERIPHERAL SMEAR FINDING } \\
\text { Anaemia }\end{array}$ & $\begin{array}{c}\text { NO. OF CASES } \\
19\end{array}$ & $\begin{array}{c}\text { OF CASES } \\
100 \%\end{array}$ \\
\hline Thrombocytopenia & 12 & $63 \%$ \\
\hline Pancytopenia & 8 & $42 \%$ \\
\hline Leucopenia & 7 & $36 \%$ \\
\hline Leucoerythroblastic picture & 6 & $31 \%$ \\
\hline Dry tap & 3 & $15 \%$ \\
\hline Rouleaux formation & 3 & $15 \%$ \\
\hline
\end{tabular}




\section{ORIGINAL ARTICLE}
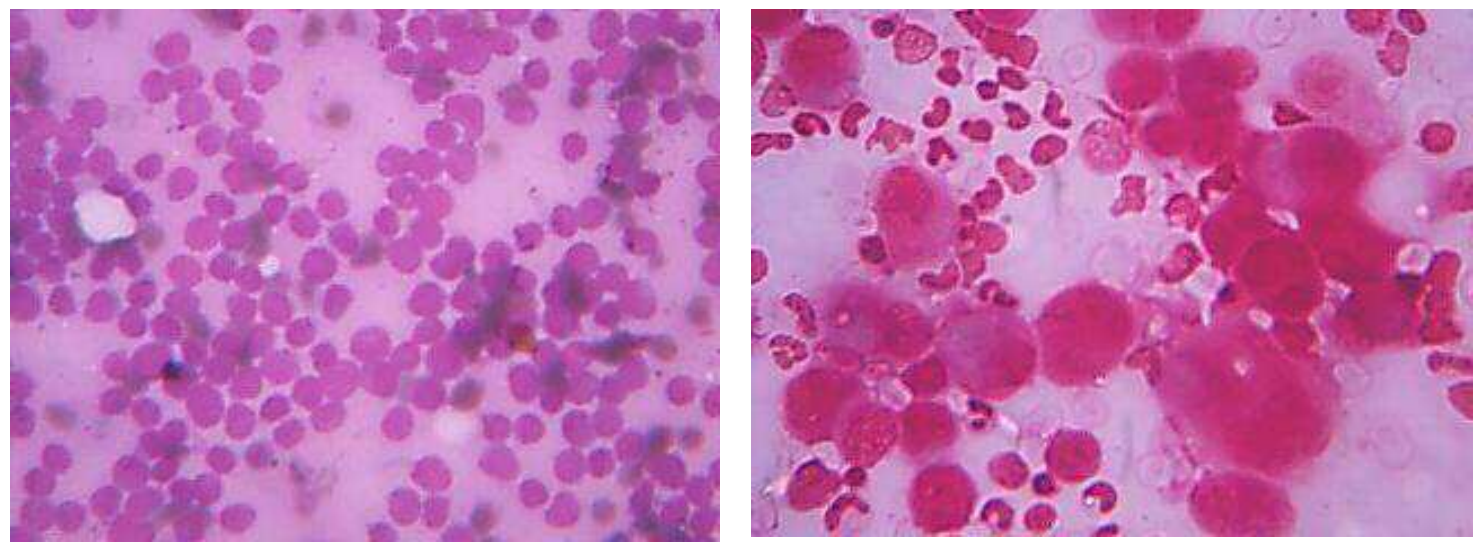

BMB: METASTATIC DEPOSITS FROM PROSTATE IHC-ER-POSITIVE IN BREAST METS TO BONE MARROW
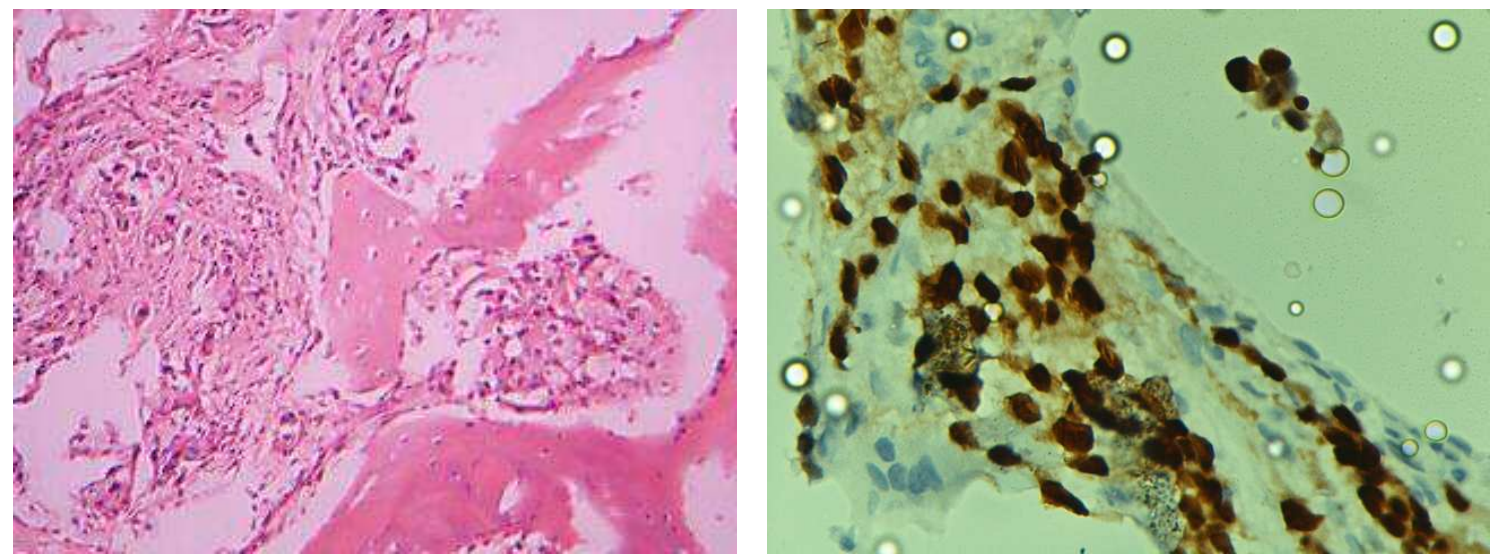

ROULEAUX FORMATION - MULTIPLE MYELOMA IMPRINTS OF BM- MULTIPLE MYLOMA
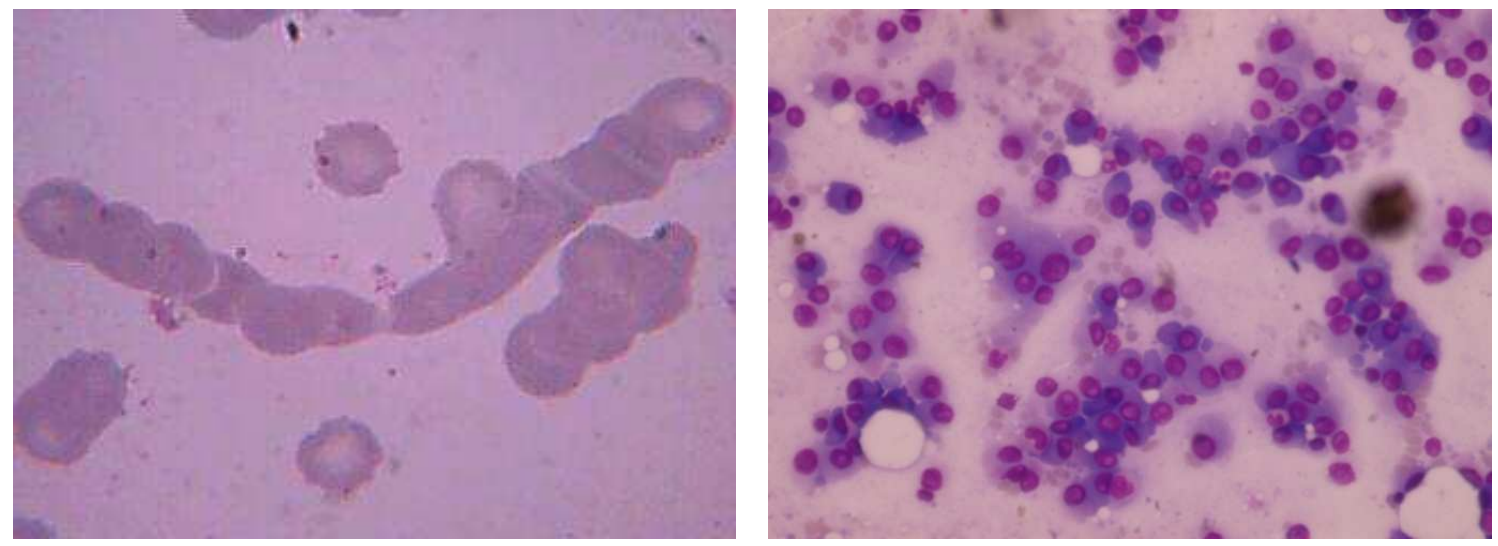

Journal of Evolution of Medical and Dental Sciences/Volume1/ Issue3/July-Sept 2012. Page 163 
EPITHELOID CELLS - GRANULOMA

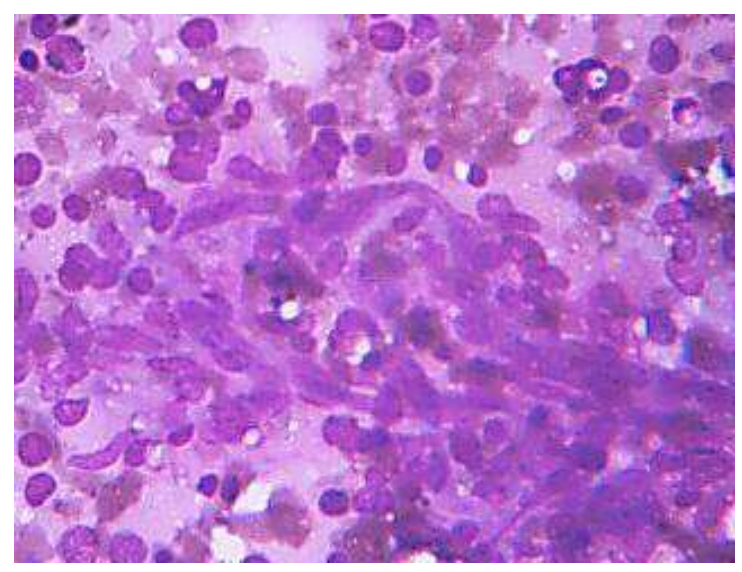

\section{GELATINOUS TRANSFORMATION OF BM}

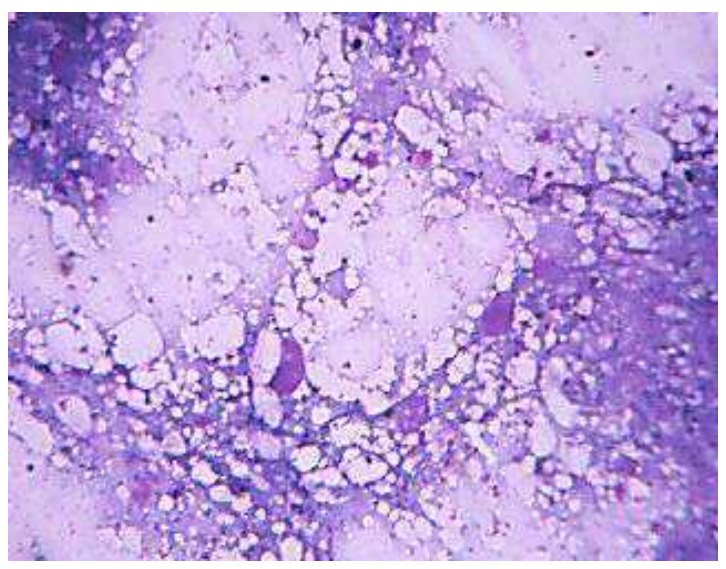

DISCUSSION : Bone marrow examination is very useful in the evaluation of hemato-oncological disorders. Common findings in the peripheral blood - leucoerythroblastic blood picture, Pancytopenia, rouleaux formation. Bone marrow aspirates and trephine biopsies are sensitive techniques for detecting bone marrow pathology. Trephine biopsy is more sensitive than bone marrow aspiration and sensitivity is increased by performing bilateral biopsies or by obtaining a single large biopsy.

In adolescent individuals who were eventually diagnosed with Lymphoma/leukemia, they initially showed pancytopenia with occasional atypical cells in the peripheral smear. Dry tap was seen in both the cases. Imprint smears from bone marrow biopsy showed that the marrow was packed with blasts.

Renal failure, low back pain and male predominance was common in all the cases of multiple myeloma. All the four cases showed elevated levels of serum creatinine.

Marrow infiltration may be focal or diffuse. Reticulin and collagen fibrosis are commonly present in bone marrow with metastasis. Fibrosis is more in case of greater degree of marrow infiltration. Marked fibrosis is most common in carcinoma of breast, stomach, prostate, lung. Marked fibrosis causes pancytopenia, chemotherapeutic drugs causes haemotoxicity, all these carries bad prognosis. The two primary sites whose identification is most important because of their sensitivity to hormonal therapy are breast and prostate. The presence of bone marrow metastasis is helpful in detecting hormonal receptor status when it was not done on primary tumour.

In children spleenic aspirate is supplementary to bone marrow aspiration in identification of storage disorders. Neuroblastoma metastasis to bone marrow is very rare in children less than one year age.

CONCLUSION: Bone marrow aspiration and trephine biopsy are effective and cheap methods of evaluating various pathological lesions, more useful especially in visceral tumours metastasizing to bone marrow. Bone marrow examination is indicated when there is significant probability of identifying lesion which would affect the treatment of primary lesion. Bone marrow examination itself sometimes gives clue to primary pathology. Imaging techniques like radionucleide bone scan MRI, CT are usually less effective when compared to bone marrow examination. 


\section{REFERENCES:}

1. Singh G, Krause JR, Breit feld V (1977) Bone marrow examination for metastatic tumor, Cancer 40:2317-2321.

2. Finkelstein JZ, Ekert H, ISSACSH, Higgins G (1970) Bone marrow metastases in children with solid tumors. Amj Dis child 119:49-52.

3. Moid F, Depalma L (2005) comparison of relative value of bone marrow aspirater and bone marrow trephine biopsies in the diagnosis of solid tumors metastasis and Hodgkins Lymphoma. Institutional experience and literature review Arch Pathol Lab Med 129:497-501.

4. Gangadeep Kaur, Metastatic bone marrow tumors: study of nine cases and review of the literature J Blood Disorder Transfus 2011, 2:3.

5. Saadettin Kilickap, Bone marrow metastasis of solid tumors: Clinicopathological evaluation of 73 cases: Turkish journal of cancer.

6. Atac B, Lawrence C, Goldberg SN, metastatic tumor: the complementary role of the marrow aspinate and biopsy. Amj Med SCi, 1991; 302:211-213.

7. Nanda A, Basus, Marwaha N. Bone marrow trephine biopsy as an adjunct to bonemarrow aspiration. J Assoc physicians India, 2002:50:893-895.

8. Bearden JD, Ratkin GA, Coltman CA Comparison of the diagnostic value of bone marrow biopsy and bone marrow aspiration in neoplastic disease. J clin pathol. 1974:27:738740.

9. Bone marrow pathology, fourth edition B.J. Bain, D.M. Clark and B.S. Wilkins (c) 2010 Barbara.j. Bain, David M. Clark, Bridget S. Wilkins ISBN:978-1-405-16825-0.

10. Jonsson U, Rundles RW (1951) tumor metastases in bone marrow: Blood 6:16-25.

11. Papac RJ (1994) bone marrow metastases-A review cancer 74:2403-2413.

12. Savage RA. Hoffman GC, Shakar K (1978) Diagnostic problems involved in detection of metastatic neoplasms by bone marrow aspinate compared with needle biopsy Amj Clin Pathol 70:623-627. 